\title{
Progress toward the Total Synthesis of Frondosin C
}

\author{
Xin Li, Robert E. Kyne, and Timo V. Ovaska \\ Connecticut College, Department of Chemistry, 270 Mohegan Avenue, New London, CT 06320, \\ USA
}

\section{Abstract}

A straightforward approach toward the total synthesis of frondosin C is described. This strategy involves a key one-pot, microwave-assisted 5-exo cyclization-Claisen rearrangement sequence that was used for the expedient assembly of the frondosic C scaffold. Subsequent manipulation of the tetracyclic core allowed the synthesis of an advanced intermediate bearing the characteristic diene moiety in the $\mathrm{B}$ ring.

Five novel sesquiterpene hydroquinone derivatives, frondosins A-E (Figure 1), were recently isolated from the Micronesian marine sponge Dysidea frondosa. ${ }^{1}$ Frondosins A and D, having opposite optical rotations compared to those present in Dysidea frondosa, have also been found in another sponge, Euryspongia sp. ${ }^{2}$ All members of the frondosin family are antagonists of interleukin-8 (IL-8) and inhibitors of protein kinase C (PKC) in the low micromolar range. ${ }^{1}$ IL-8 is a neutrophil-activating peptide, which is produced by several cell types in response to inflammatory stimuli. ${ }^{3}$ It is now known to also play an important role in tumor progression and metastasis in several human cancers, ${ }^{4}$ including lung cancers. ${ }^{4 b}$ Thus, IL- 8 antagonists hold therapeutic potential as novel anti-inflammatory agents for the treatment of several acute and chronic inflammatory disorders, such as rheumatoid arthritis, psoriasis and many lung diseases, including acute respiratory distress syndrome, chronic obstructive pulmonary disease and asthma. In addition, IL-8 represents a potential new target for antiretroviral therapy against HIV $-1,2,4 \mathrm{~b}, 5$ and inhibitors of IL-8 action may prove useful therapeutic agents against cancer as inhibitors of tumorigenesis and proangiogenesis. ${ }^{4}$

Total synthesis of frondosin B was first achieved by Danishefsky et al. ${ }^{6}$ in 2000 and, more recently, by the Trauner ${ }^{7}$ and Flynn ${ }^{8}$ groups. Other members of the frondosin family, however, have not yet been synthesized.

We recently reported the first known approach to the tetracyclic frondosin $\mathrm{C}$ ring system. ${ }^{9}$ This approach is based on our ongoing investigations involving a base-catalyzed tandem cyclization/Claisen rearrangement as a convenient route to cycloheptane-containing polycyclic ring structures. ${ }^{10}$ The reaction sequence involves an initial 5-exo dig cyclization of an appropriately substituted 4-alkyn-1-ol system followed by in situ microwave-assisted Claisen rearrangement of the intermediate 2-alkylidene tetrahydrofuran derivative. ${ }^{11}$

Herein, we wish to report our progress toward the total synthesis of frondosin C. At the outset of the current investigation, it was envisaged that tetracycle 2 , previously synthesized from the tertiary alcohol 1 (Scheme 1), ${ }^{9}$ could be manipulated to frondosin $\mathrm{C}$ in a sequence of steps involving $\alpha$-methylation, generation of the requisite $\mathrm{B}$ ring diene functionality, demethylation of the methoxy group and oxidation of the resulting phenol system to the $p$-quinol moiety.

tvova@ conncoll.edu . 
According to this plan, the requisite $\mathrm{C} 8$ methyl group was first introduced by treatment of 2 with NaHMDS followed by addition of MeI. It was anticipated that, due to the proximity of the A ring gem dimethyl moiety to $\mathrm{C} 6$, methylation at $\mathrm{C} 8$ would predominate in this reaction. In fact, this turned out to be the case although the observed regioselectivity was found to be rather modest; the desired ketone $\mathbf{3}$ and the $\mathrm{C} 8$ methylated $\mathbf{4}$ were formed as a 2.4 to 1 mixture of regioisomers (Scheme 2). ${ }^{12}$ It is noteworthy that stereoselectivity of the alkylation affording 3 was high, consistent with delivery of the electrophile from the less hindered top face of the intermediate enolate anion.

All attempts to improve regioselectivity of the methylation, including through the use of different bases, were unsuccessful and this strategy was ultimately abandoned. Instead, a different approach involving introduction of the requisite methyl group early on in the sequence was implemented. According to this strategy, readily separable isomeric ketones $\mathbf{6}$ and $\mathbf{7}$, each bearing a methyl group at the propargylic position, were prepared in $70 \%$ overall yield from commercially available 6-methoxy-1-indanone as shown in Scheme 3.

The subsequent coupling reaction involving 1-iodo-3,3-dimethylcyclohexene ${ }^{10 \mathrm{e}}$ and one of the diastereomeric ketones, randomly assigned as $\mathbf{6}$, was effected employing our usual protocol $^{10}$ to provide tertiary alcohol $\mathbf{8}$ in $85 \%$ yield (Scheme 4 ).

Following treatment with TBAF and exposure to microwave irradiation (MWI) in the presence of catalytic MeLi ( $\sim 0.1$ equiv), 8 was smoothly converted to a 2.5:1 mixture of tetracyclic ketones $\mathbf{3}$ and $\mathbf{9}$ (Scheme 4). Given that the cyclization/Claisen rearrangement sequence involves a single diastereomer derived from $\mathbf{8}$, the formation of a mixture of isomeric ketones $\mathbf{3}$ and $\mathbf{9}$ in the process is intriguing and most likely arises from the interconversion of exocyclic intermediates $\mathbf{1 0}$ and $\mathbf{1 2}$ via the endocyclic intermediate $\mathbf{1 1}$ as depicted in Scheme 5. ${ }^{13}$

Further evidence for the suggested mechanism is provided by the observation that an identical diastereomer ratio of tetracyclic ketones $\mathbf{3}$ and $\mathbf{9}$ is obtained when a 1:1 mixture of isomeric alcohols $\mathbf{1 3}$ and $\mathbf{1 4}$ is subjected to catalytic MeLi and MWI (Scheme 6). Indeed, the entire reaction sequence depicted in Schemes 3 and 4 may be conducted with the same end result starting with hydrazone $\mathbf{5}$ and performing the subsequent steps without prior separation of the diastereomeric intermediates.

Calculation of minimum energy conformations for compounds 3 and 9 revealed an energy difference of $8.57 \mathrm{~kJ} / \mathrm{mol}$ in favor of $\mathbf{3}^{14}$ This being the case, it was envisioned that isomerization of the mixture could provide an opportunity to increase the $\mathbf{3 / 9}$ ratio further.

The initial isomer ratio of 2.5 to 1 was significantly improved in favor of $\mathbf{3}$ without loss of product material when the mixture was treated with several different bases. The highest observed ratio of 14.6 to 1 (94\% de) resulted from refluxing a mixture of $\mathbf{3}$ and $\mathbf{9} \mathrm{in} t$-BuOK/ $t$-BuOH for 3.5h. Stereochemistry of the major isomer was confirmed by a combination of $2 \mathrm{D}$ NMR and 1D NOESY techniques and the experimental observations are in good agreement with the calculated trends.

Removal of the carbonyl functionality was achieved by a three-step sequence involving an initial borohydride reduction, then conversion of the resulting alcohol 15 to the corresponding mesylate and treatment of the mesylate with lithium triethylborohydride (Scheme 7).

It should be noted that several other deoxygenation methods that were attempted, including $\mathrm{Ra}-\mathrm{Ni}$ reduction of a thioacetal, prepared from 3 and 1,2-ethanedithiol, as well as $\mathrm{NaCNBH}_{3}$ treatment of a tosylhydrazone derived from $\mathbf{3}$, were overall less satisfactory in providing $\mathbf{1 6}$. 
Somewhat surprisingly, treatment of $\mathbf{1 6}$ with $\mathrm{PhSeBr}$ in DMF resulted in direct and rapid generation of diene $\mathbf{1 7}$ in $86 \%$ yield. Although it was anticipated that $\mathbf{1 7}$ could be readily converted to the desired diene 18, this turned out not to be the case (Scheme 7) and all attempts at effecting isomerization of the trisubstituted double bond in $\mathbf{1 7}$ failed. However, it was found that 18 could be produced as the major product along with 17 (2.3:1 ratio) in a two-step sequence involving reaction of $\mathbf{1 6}$ with $m$-CPBA, followed by treatment of the resulting unstable epoxide 19 with 2.0 equivalents of $\mathrm{BF}_{3} \cdot \mathrm{OEt}_{2}$ (Scheme 7).

In an attempt to find a more reliable method to install the desired diene moiety in the B ring, tetracyclic ketone 3 was subjected to DDQ oxidation. ${ }^{18}$ Gratifyingly, this resulted in direct formation of diene $\mathbf{2 0}$ in $90 \%$ yield (Scheme 8). Borohydride reduction of the carbonyl group followed by reaction with mesyl chloride and triethylamine resulted in in situ elimination of the intermediate mesylate, affording triene $\mathbf{2 2}$ in high yield. Alternatively, $\mathbf{2 2}$ could be obtained in a comparable yield by subjecting alcohol 21 to phosphorous oxychloride in pyridine. Finally, diimide reduction of $\mathbf{2 2}$ afforded racemic diene $\mathbf{1 8}$ in $\mathbf{7 0 \%}$ yield.

In summary, we have achieved the synthesis of an advanced intermediate $\mathbf{1 8}$ bearing most of the characteristic structural features of frondosin C. Efforts to complete the total synthesis of this natural product as well as other members of the frondosin family are currently underway in our laboratories.

\section{Supplementary Material}

Refer to Web version on PubMed Central for supplementary material.

\section{Acknowledgment}

This research was supported by grants from the National Institutes of Health (NIGMS), and the Camille and Henry Dreyfus Foundation (Scholar-Fellow Program). T.V.O also gratefully acknowledges support from the Hans and Ella McCollum-Vahlteich ' 21 endowment. R.E.K. gratefully acknowledges support from Bristol-Myers Squibb (summer undergraduate fellowship).

\section{References}

1. Patil AD, Freyer AJ, Killmer L, Offen P, Carte B, Jurewicz AJ, Johnson RK. Tetrahedron 1997;53:5047.

2. Hallock YF, Cardellina JH II, Boyd MR. Nat. Prod. Lett 1998;11:153.

3(a). Seitz M, Dewald B, Gerber N, Baggiolini M. J. Clin. Invest 1991;87:463-469. [PubMed: 1899427] (b) Miller EJ, Cohen AB, Nagao D, Griffith RJ, Maunder RJ, Martin TR, Weiner-Kronish JP, Sticherling M, Christophers E, Matthay MA. Am. Rev. Respir. Dis 1992;146:247.

4(a). Brat DJ, Bellail AC, Van Meir EG. Neuro-oncol 2005;7:122. [PubMed: 15831231] (b) Zhu YM, Webster SJ, Flower D, Woll PJ. Br. J. Cancer 2004;91:1970. [PubMed: 15545974] (c) Yuan A, Chen JJ, Yao PL, Yang PC. Front. Biosci 2005:853. [PubMed: 15569594]

5. Lane BR, Lore K, Bock PJ, Andersson J, Coffey MJ, Strieter RM, Markovitz DM. J. Virol 2001;75:8195. [PubMed: 11483765]

6(a). Danishefsky SJ, Inoue M, Frontier AJ. Angew. Chem., Int. Ed 2000;39:761. (b) Inoue M, Carson MW, Frontier AJ, Danishefsky SJ. J. Am. Chem. Soc 2001;123:1878. [PubMed: 11456808]

7(a). Hughes CC, Trauner D. Angew. Chem., Int. Ed 2002;41:1569. (b) Hughes CC, Trauner D. Tetrahedron 2004;60:9675.

8. Kerr DJ, Willis AC, Flynn BL. Org. Lett 2004;6:457. [PubMed: 14961597]

9. Martinez I, Alford PE, Ovaska TV. Org. Lett 2005;7:1133. [PubMed: 15760157]

10(a). Ovaska TV, Roark JL, Shoemaker CM. Tetrahedron Lett 1998;39:5705. (b) Ovaska TV, Roses JB. Org. Lett 2000;2:2361. [PubMed: 10930284] (c) Ovaska TV, Reisman SE, Flynn MA. Org. Lett 2001;3:115. [PubMed: 11429851] (d) Ovaska TV, Ravi Kumar JS, Hulford CA, O’Sullivan 
MF, Reisman SE. Tetrahedron Lett 2002;43:1939. (e) McIntosh CE, Martinez I, Ovaska TV. Synlett 2004:2579.

11. For an early report of this sequence, see Marvell EN, Titterington D. Tetrahedron Lett 1980:2123.

12. The stereochemistry at $\mathrm{C} 8$ of compound $\mathbf{4}$ could not be determined with certainty.

13. Rhoads SJ, Brandenburg CF. J. Am. Chem. Soc 1971;93:5805.

14. The minimum energy conformations shown were calculated using MacroModel v. 9.0015 with the MM3* forcefield and a GB/SA chloroform solvent model. ${ }^{15}$ Structures were generated by a 10,000 step large scale low-mode conformational search. 16,17

15. Still WC, Tempczyk A, Hawley RC, Hendrickson T. J. Am. Chem. Soc 1990;112:6127.

16. Keseru GM, Kolossvary I. J. Am. Chem. Soc 2001;123:12708. [PubMed: 11741448]

17. Keseru GM, Kolossvary I. J. Comput. Chem 2001;22:21.

18. Baran PS, Guerrero CA, Corey EJ. J. Am. Chem. Soc 2003;125:5628. [PubMed: 12733890] 


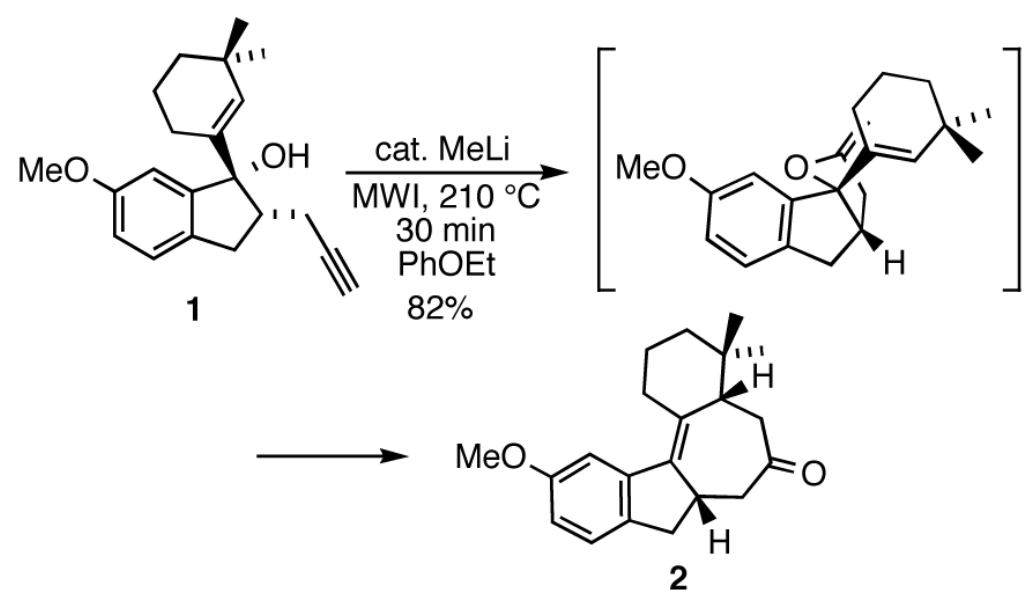

Scheme 1.

Synthesis of frondosin C tetracyclic core. 


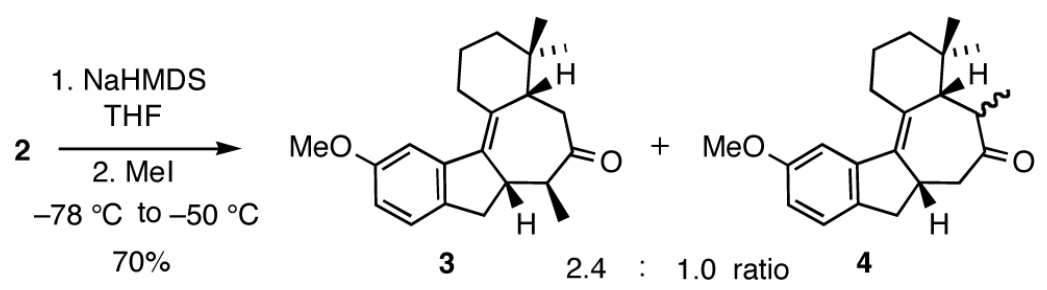

Scheme 2.

Methylation of ketone $\mathbf{2}$. 


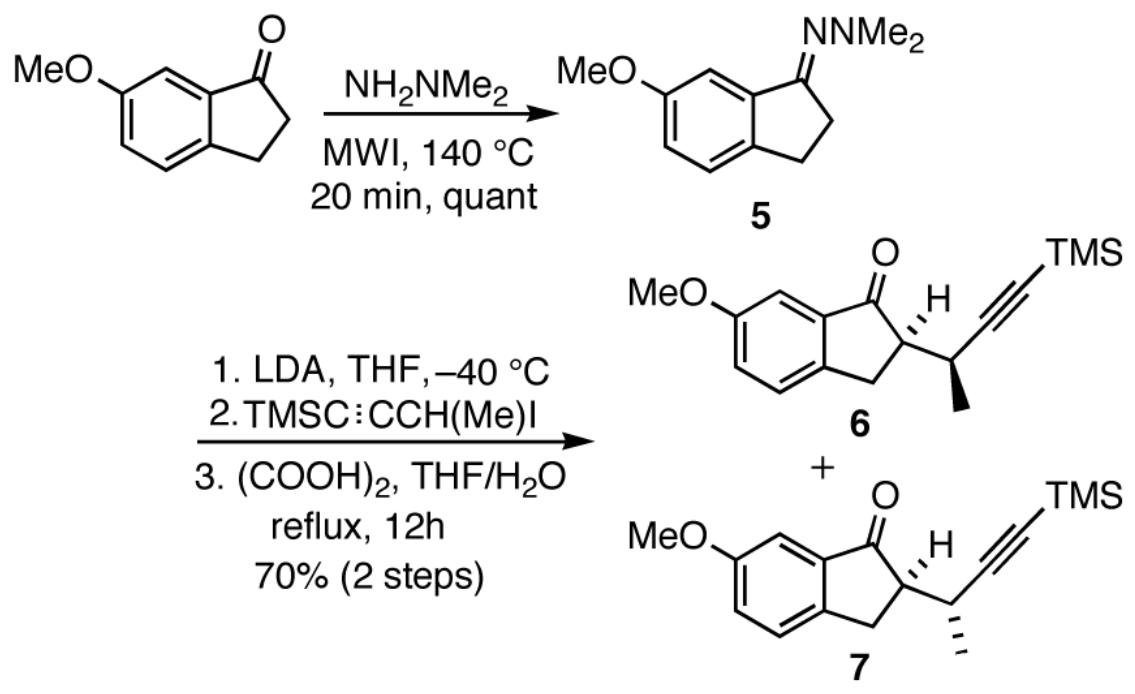

Scheme 3.

Introduction of the C8 methyl group. 

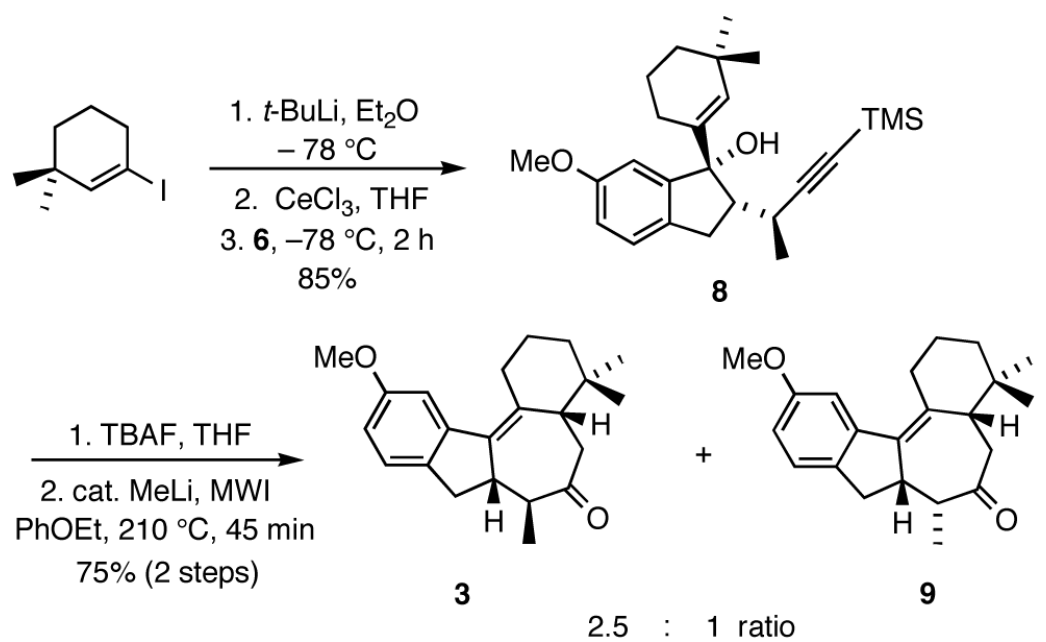

Scheme 4.

Preparation of tetracyclic ketones $\mathbf{3}$ and $\mathbf{9 .}$ 
<smiles>COc1ccc2c(c1)[C@](O)(C1=CCC(C)(C)CC1)[C@H]([C@@H](C)C#C[As])C2</smiles>

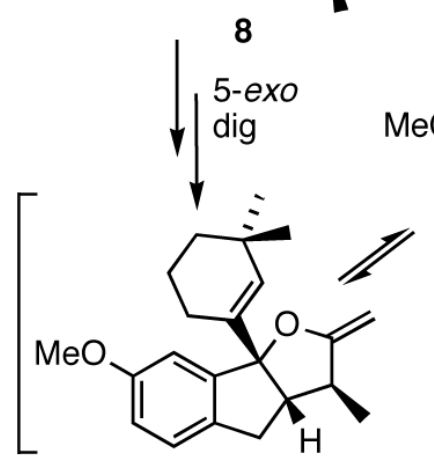

10

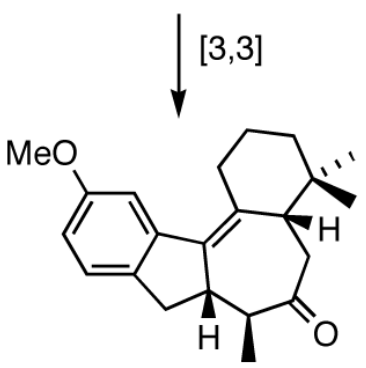

3<smiles>CC1=C(C)[C@H]2Cc3ccccc3[C@]2(C2=CCC(C)(C)CC2)O1</smiles>

11

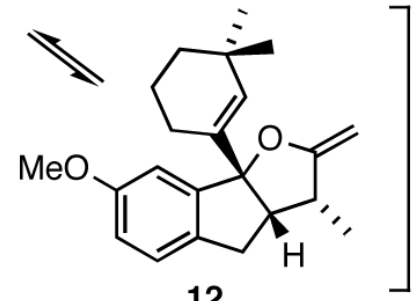

$[3,3]$

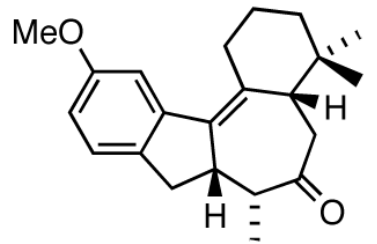

9

Scheme 5.

Proposed interconversion of intermediates $\mathbf{1 0}$ and $\mathbf{1 2 .}$ 


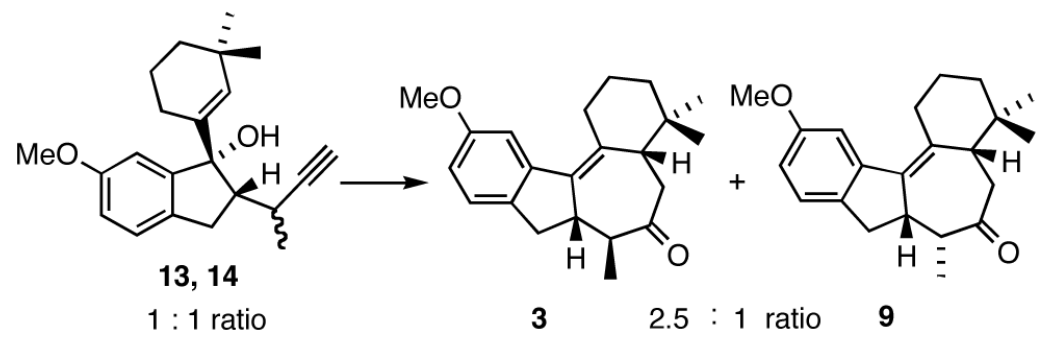

Scheme 6.

Cyclization/Claisen rearrangement sequence involving a diastereomeric mixture of acetylenic alcohols 13 and 14. 

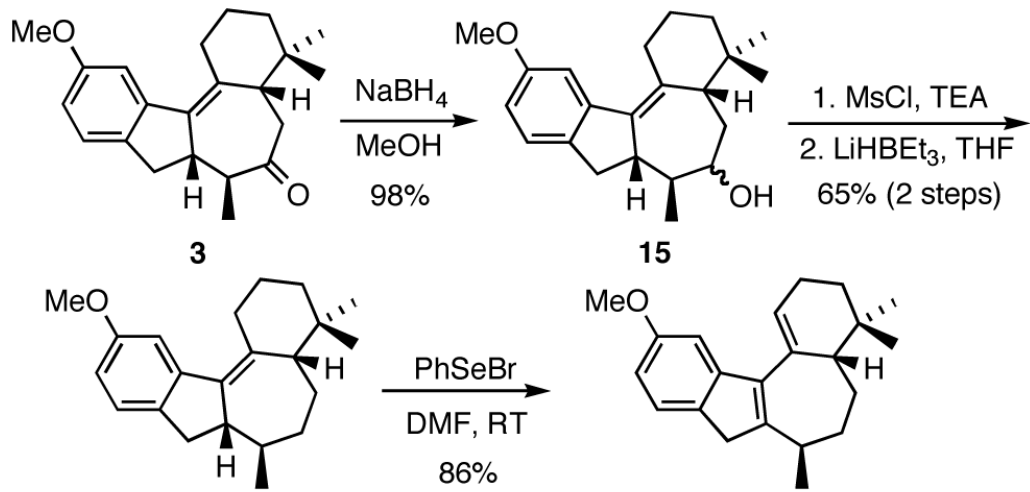

16

17
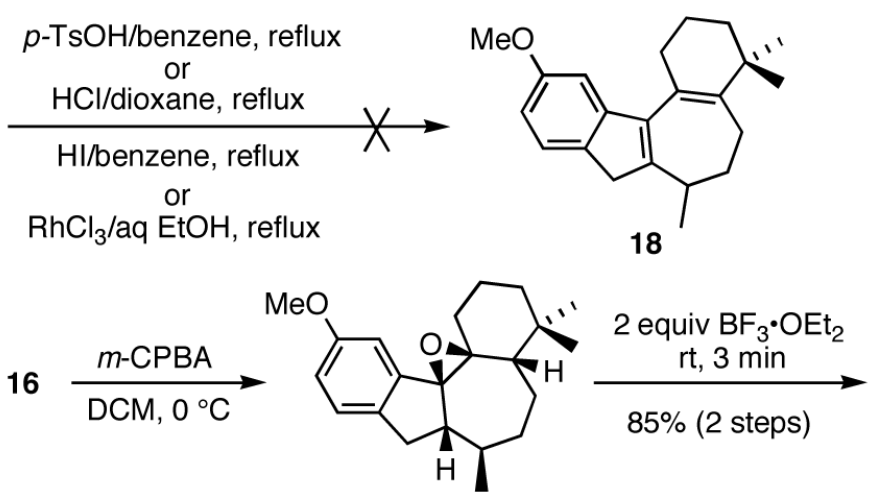

19

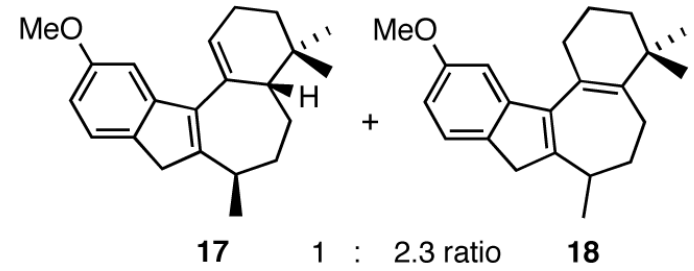

Scheme 7.

Initial strategies for the synthesis of $\mathbf{1 8}$. 

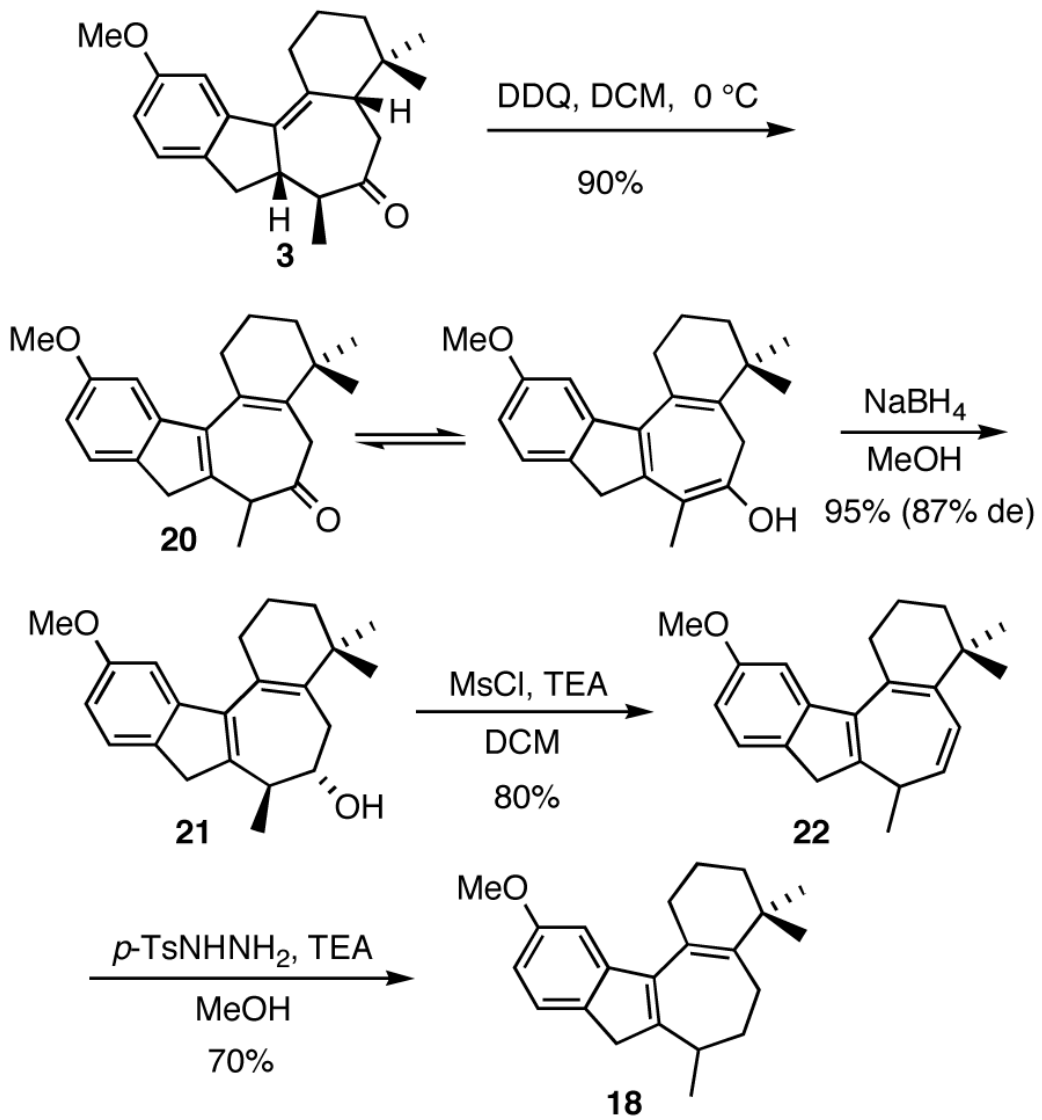

Scheme 8.

Improved synthesis of $\mathbf{1 8}$. 


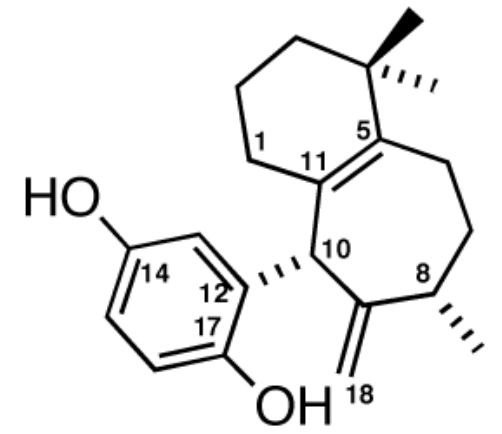

Frondosin A

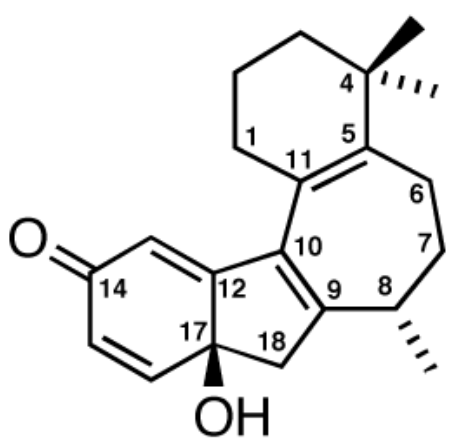

Frondosin C

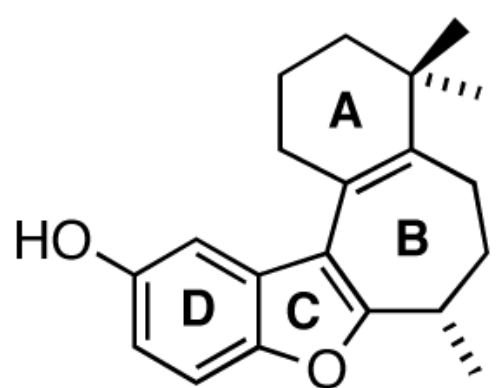

Frondosin B

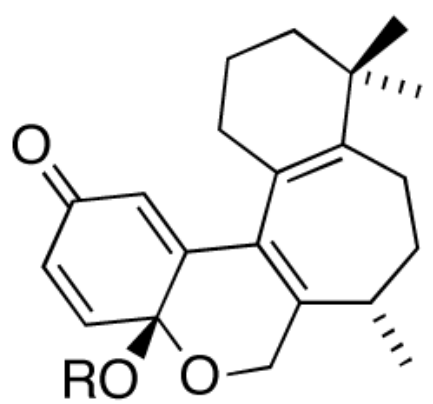

Frondosin $\mathrm{D}(\mathrm{R}=\mathrm{H})$

Frondosin $\mathrm{E}(\mathrm{R}=\mathrm{Me})$

Figure 1.

Structures of frondosins A-E. 


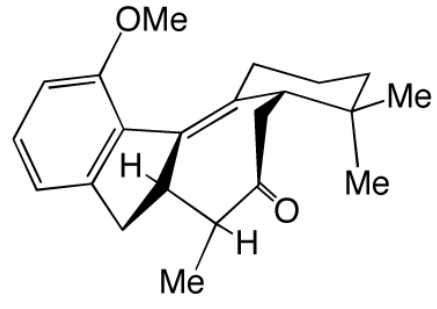

3

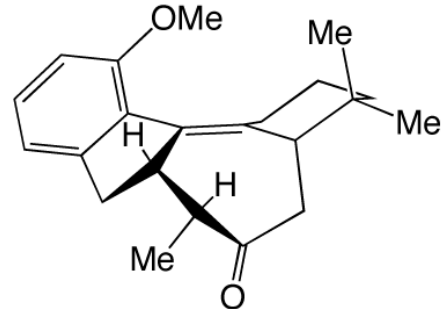

9

Figure 2.

Calculated minimum energy conformations of $\mathbf{3}$ and $\mathbf{9 .}$ 